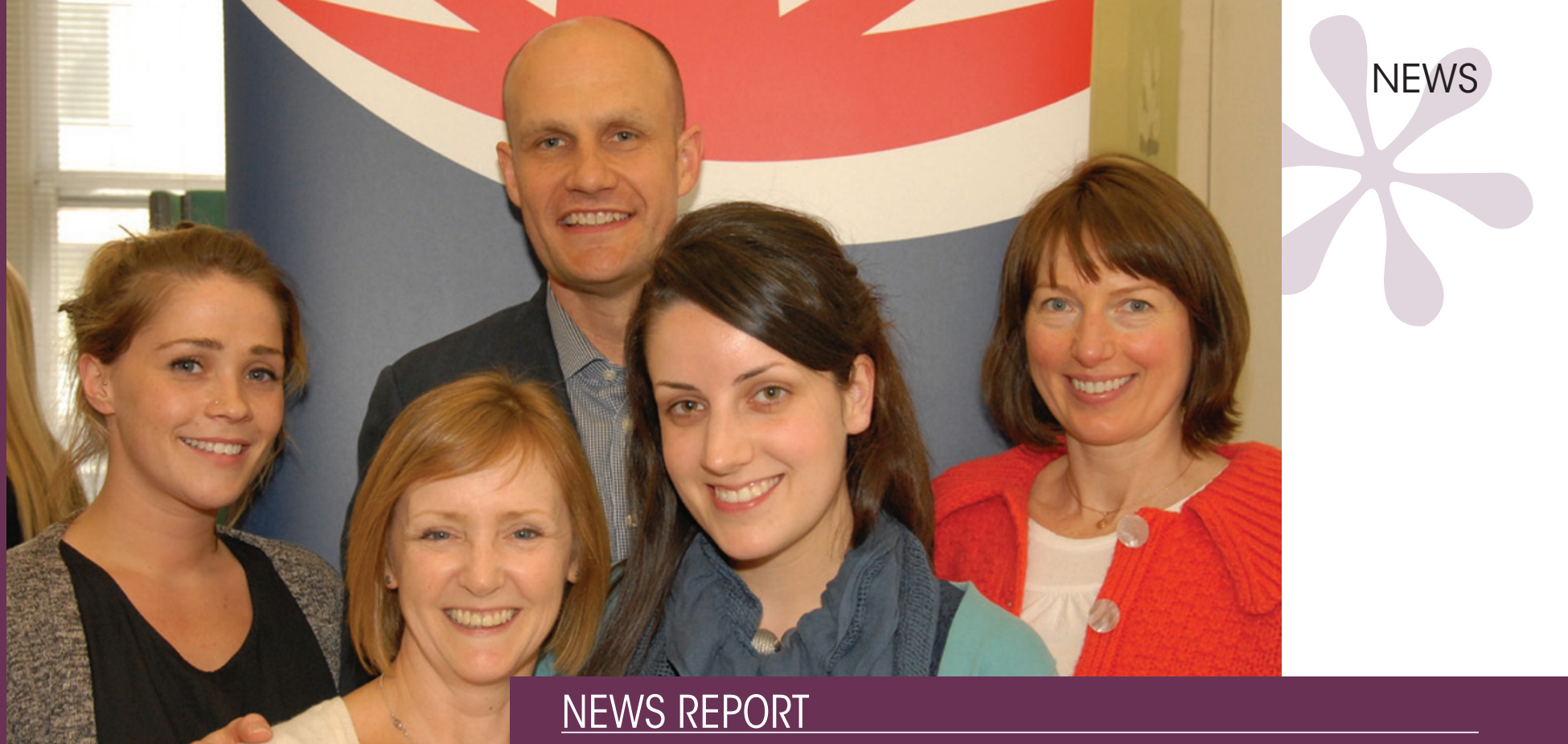

\title{
AN INTRODUCTION TO LINGUAL ORTHODONTICS
}

\section{By Helen Lindup, orthodontic dental nurse}

Helen Lindup (far right) attending the introduction to lingual orthodontics

\section{FIRST EMSWORTH CPD CLUB}

The first Emsworth Dental Nurse Study Club evening was attended by 40 dental nurses who enjoyed a presentation by Dr Rupal Patel on Periodontology: an update for dental nurses.

The talk involved group work for the dental nurses attending which helped to 'break the ice' and focus on the topic at hand.

Organiser Mary-Anne Worthington RDN said: 'As I have had a lot of interest from local dental hygienists, the next CPD evening will be open to both dental nurses and dental hygienists. It will be held on 4 February at The Brookfield Hotel, Emsworth. The speaker will be Lt Col Neil Mackenzie, a maxillofacial consultant at QA Hospital Portsmouth. The talk will be on historical facial reconstruction from World War I to the present day'.

At the February event registration is from $6 \mathrm{pm}$, the talk will start at 6.30pm and last for an hour and 15 minutes and the cost is $£ 12$ per person including refreshments.

Find out more at: www.theednsc.co.uk.

$$
\begin{aligned}
& \text { THE } \\
& \text { BDJ TEAM } \\
& \text { FACEBOOK PACE } \\
& \text { LAUNCHES } \\
& \text { IN 2014! }
\end{aligned}
$$

It was a bright and blustery day when I joined a group of orthodontic nurses and therapists at the British Orthodontic Society (BOS) headquarters in London. We were there for an Introduction to Lingual Orthodontics for nurses and therapists and our speakers were Paul Ward, Richard George and Angela Auluck, all committee members of the British Lingual Orthodontic Society (BLOS).

The two parts of the day that I found most interesting were the history of lingual orthodontics and the opportunity to see and handle the different systems.

In the 1970s an American orthodontist, Dr Craven Kurz, came up with the lingual concept when he was driving along the freeway trying to work out how he could straighten a woman's teeth so she would not lose her job as a bunny girl. He decided he would put the brackets on the inside and with the help of Ormco developed his braces further. At the same time in Japan Professor Kinya Fujita developed his lingual braces and the mushroom arch for martial arts combatants.

For a lot of orthodontists the high costs, difficult mechanics and disappointing results dampened much of the initial enthusiasm. Dr Didier Fillion was one of the few to remain committed to the technique and maintained a full time lingual orthodontic practice in Paris and in London.

Dr Fillion invented Orapix, a straight wire system based on CAD/CAM technology. This is a partially customised system whereby you send impressions and the brackets to a lab. The technician puts the brackets onto a model and trays are made around the brackets so the orthodontist just puts glue on the brackets, puts the tray in the mouth and the glue is set, either chemically or using light.

This helped create a resurgence in the 1990s and in 2000 Dr Dirk Wiechmann created Incognito, a fully-customised system whereby the laboratory makes bespoke braces and wires and these are sent back in trays for the orthodontist to cement onto his patient's teeth.

After a very good lunch, the second part of the day I enjoyed was talking to the reps and actually seeing the braces that were discussed throughout the day. The variety of brackets and systems was amazing, as was the evolution of the lingual bracket, from big and bulky mass produced brackets to lower profile brackets with a larger surface area at the base for greater bonding strength.

As one of the nightmares of lingual braces is a breakage, putting the bracket back in the correct position can be a challenge. This is usually done freehand or by cutting the tray the brackets came in, putting the bracket in the tray and bonding it back on that way. One of the custom made brackets (Harmony by American Orthodontics) had little positioning jigs. Forestadent were there with their $2 \mathrm{D}$ lingual direct bonding brackets. The $3 \mathrm{M}$ Incognito reps let us all have a go at ligating the archwire using David Burdess pliers - very fiddly!

This was the first ever lingual meeting for orthodontic nurses and therapists organised by BLOS and I very much hope it won't be the last. 